Journal of Animal and Veterinary Advances $10(7): 853-857,2011$

ISSN: $1680-5593$

(C) Medwell Journals, 2011

\title{
Effect of Orally-Administered 17 $\alpha$-Methyltestosterone at Different Doses on the Sex Reversal of the Nile Tilapia (Oreochromis niloticus, Linneaus 1758)
}

\author{
${ }^{1}$ Ihsan Celik, ${ }^{2}$ Yusuf Guner and ${ }^{1}$ Pinar Celik \\ ${ }^{1}$ Department of Aquaculture, Faculty of Fisheries, \\ Canakkale Onsekiz Mart University, Terzioglu Campus, 17100 Canakkale, Turkey \\ ${ }^{2}$ Department of Aquaculture, Faculty of Fisheries, Ege University, 35100 Bornova, Izmir, Turkey
}

\begin{abstract}
In order to obtain all male population, the Nile tilapia (Oreochromis niloticus) larvae which just finished the yolk sac were fed with feed containing $17 \alpha$-Methyltestosterone at five different doses $(0,20,30$, 40,50 and $60 \mathrm{mgMT} \mathrm{kg}^{-1}$ feed) for 28 days. As a result of the experiment repeated twice, it was found out that the sex reversal rates among the groups were at the levels of $57.1,69.8,69.4,70.9,86.1$ and $93.7 \%$, respectively. Furthermore, it was observed that the highest sex reversal rate occurred in the group to which $60 \mathrm{mgMT} \mathrm{kg}{ }^{-1}$ feed dose was applied.
\end{abstract}

Key words: Tilapia, Oreochromis niloticus, sex reversal, $17 \alpha$-methyltestosterone, doses, population

\section{INTRODUCTION}

With the purpose of achieving more productivity in growing tilapia (Oreochromis niloticus) at the unit time and obtaining more uniform individuals in terms of body size, it is important to produce monosex cultures that are totally composed of males (Mair and Little, 1991). Although, monosex male populations can be obtained by direct or indirect methods, the oral administration of $17 \alpha$-Methyltestosterone (MT) has been reported to be the most preferred method in commercial uses (Mair and Little, 1991; Vera Cruz and Mair, 1994; Green and Teichert-Coddington, 2000). The sex reversal application among tilapia by this method is quite effective in obtaining a population, almost all of which is composed of male individuals and $\leq 5 \%$ of which is composed of phenotypic females in the early life stage (Green and Teichert-Coddington, 2000).

Although, feed containing MT at $60 \mathrm{mgMT} \mathrm{kg}^{-1}$ feed dose is used generally for the newly-hatched individuals in the sex reversal studies with oral administration (Pompa and Green, 1990) and although, it is reported that the general dose used in Nile tilapia juveniles was at $30-60 \mathrm{mgMT} \mathrm{kg}{ }^{-1}$ feed interval until the 25-60th days of early feeding (Macintosh and Little, 1995) many studies have been carried out (Abucay, 1997; Rosenstein and Hulata, 1994; Vera Cruz et al., 1996) and are still being carried out for optimizing the oral method of sex reversal considering the parameters such as hormone dose, the commencement time for application, application duration and stock density. This study also observes the effect of different doses of MT $\left(0,20,30,40,50\right.$ and $60 \mathrm{mgMT} \mathrm{kg}^{-1}$ feed) under controlled conditions on the sex reversal of tilapia. It is reported that sex reversal is applied to 2-6 million fish annually in the greatest tilapia farms in America, one of the countries where the commercial tilapia enterprises perform intensive production and that 167-500 juveniles are subjected to the method of sex reversal each month with a view to meeting the annual production quantity (Varadaraj et al., 1994). When it is assumed that negative environmental effects may occur in the event of performing such an intensive hormone application under natural conditions (Green and Teichert-Coddington, 2000), it is essential to perform such applications in closed circuit systems or under controlled aquarium conditions. The effect of MT on the sex reversal of Nile tilapia under fully controlled aquarium conditions was observed in this study.

\section{MATERIALS AND METHODS}

Experimental design: The juveniles used in the experiments were obtained from mature individuals which were stocked in two production aquariums each of which had a water capacity of $420 \mathrm{~L}$ with a dimension of $140 \times 60 \times 50 \mathrm{~cm}$ (length $\mathrm{x}$ width $\mathrm{x}$ height) ( 6 females $/ 2$ males) and the weights of which ranged between 150 and $350 \mathrm{~g}$. The eggs were allowed to be incubated in the mount of the female. Two experiments were carried out so as to observe the effect of different doses on sex reversal. In

Corresponding Author: Ihsan Celik, Department of Aquaculture, Faculty of Fisheries, Canakkale Onsekiz Mart University, Terzioglu Campus, 17100 Canakkale, Turkey 
the 1 st experiment, 360 of the larvae obtained after one gestation from a single female were stocked as 60 larvae (4 larvae $\mathrm{L}^{-1}$ ) in each of the 6 aquariums with a water capacity of $15 \mathrm{~L}$. In the 2 nd experiment, the larvae from another female were stocked with the same strategy. The females which held the fertilized eggs during reproduction in their mouth were allowed to incubate the eggs in their mouth and the yolk-sac larvae were taken from the mouth of female as soon as the eggs hatched. When $2 / 3$ of the yolk sac finished, granulated feed began to be given. The larvae which began exogenous feeding were kept in aquariums of $15 \mathrm{~L}$ on the first 40 days whereas they were kept in aquariums of $140 \mathrm{~L}$ from the 40th day until the 9th month. In order to distinguish whether, the gonads were male or female by histological observations, the fish were fed for 9 months and the experiment lasted for 9 months in total.

On the first 29 days of feeding, the fish were fed with hormone-injected feed and then they were fed with normal hormone-free feed. During the experiment, the water temperature was kept at a minimum of $20^{\circ} \mathrm{C}$ and a maximum of $28^{\circ} \mathrm{C}$ at an average level of $24 \pm 0.37^{\circ} \mathrm{C}$ and $\mathrm{pH}$ was kept at a minimum of 6.0 and a maximum of 8.2 at an average level of $7.6 \pm 0.42$. Lighting was provided with 30 -Watt fluorescent lamps in $12 \mathrm{~h}$ light and $12 \mathrm{~h}$ dark periods.

Preparing steroid-containing feed: The commercial carp feed containing $28 \%$ raw protein was used in feeding. The sizes of feed which was given in granulated form at the beginning of feeding were arranged according to fish sizes. In order to obtain feed containing $\mathrm{MT}$ at five different doses of 20-60 $\mathrm{mgMT} \mathrm{kg}^{-1}$ feed, $3,4.5,6,7.5$ and $9 \mathrm{mg}$ of MT were added, respectively to 5 granulated feed groups of $150 \mathrm{~g}$ each by the method of spraying. About $50 \mathrm{~mL}$ from $95 \%$ ethanol was used for each group in order to dissolve methyltestosterone. Only $50 \mathrm{~mL}$ of 95\% ethanol was sprayed over the feed of the control group that did not contain MT. After steroid was mixed into the feed, the feed was left to be dried at room temperature for $12 \mathrm{~h}$. After the feed was dried, it was stocked in plastic storage bags and preserved at room temperature.

Feeding protocol: The daily feeding rate was $10 \%$ of the mean body weight on the first 40 days of the experiment while it was $3-5 \%$ of the body weight on the $40-90$ th days. Feeding was provided in two meals and in equal amounts daily in all groups.

Specifying the sex reversal rates: To find out how sexual development was at the end of the experiment ( 9 months later), the gonads of the fish were removed. The gonads were fixed for 1 day in $10 \%$ formaline solution $(40 \%$ formaline $100 \mathrm{~mL}$ +pure water $900 \mathrm{~mL}$ ). Fixation was followed by dehydration, saturation and parafinization. Tissue sections were obtained in 4-micron sizes and the Hematoxylen-Eosin staining method was applied in tissue staining. Findings of sex formation in the gonads were recorded in the preparations prepared after staining. By looking at the histological gonad samples, the male/female rates in the population were found (Fig. 1 and 2).

The SPSS package program and the $\chi^{2}$-test were used in finding out the statistical significance in terms of intergroup survival rates and sex reversal rates $\mathrm{p}(0.05)$.

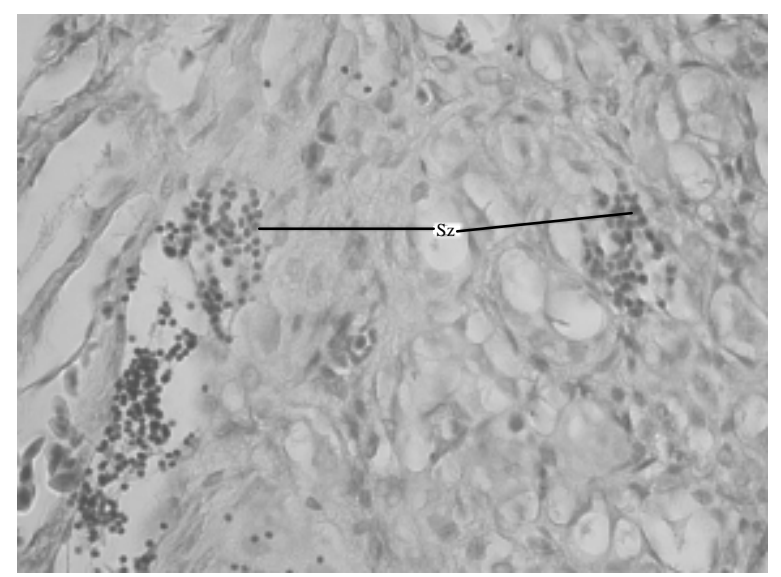

Fig. 1: The spermatozoa observed in male individuals on the gonad sections obtained at the end of the experiment and used in specifying sex, $\mathrm{Sz}$ : spermatozoa. H and E (Olympus BX51, 400X, Japan)

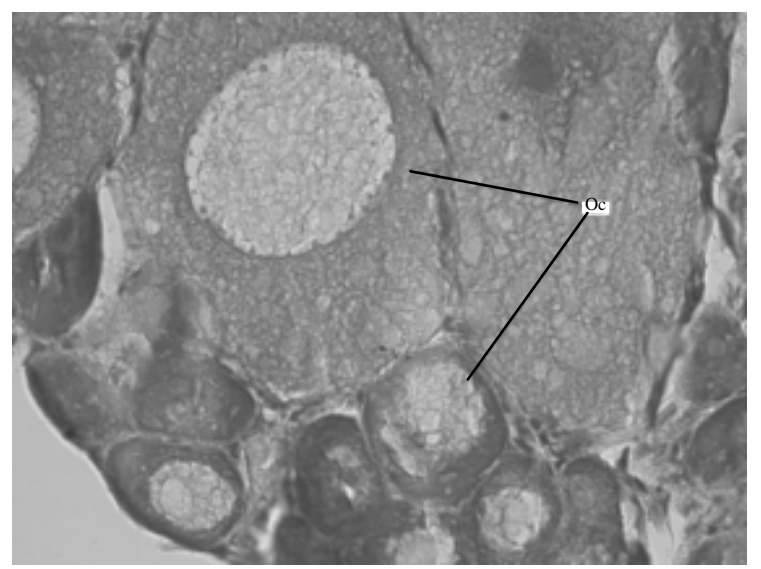

Fig. 2: The egg formations observed on the gonads of female fish, Oc: Oocyte, $\mathrm{H}$ and E (Olympus BX51, 400X, Japan) 


\section{RESULTS AND DISCUSSION}

According to the data collected in order to find out the sexes by removing the gonads of all fish so as to find out the rate of males and females in the groups at the end of the study, the survival rates were $81.6,88.3,60,91.6$, 56.6 and $80 \%$, respectively in the groups to which 0 (control), 20-60 $\mathrm{mgMT} \mathrm{kg}^{-1}$ feed was applied in the $1 \mathrm{st}$ experiment whereas they were found to be $83.7,90.2,87.4$, $78.9,82.6$ and $86.1 \%$, respectively in the 2 nd experiment (Table 1, Fig. 3). The rates of male individuals were observed to be $57.1,69.8,69.4,70.9,86.1$ and $93.7 \%$ in the 1 st experiment in each experiment tank in different groups at the end of the experiment while they were found to be $49.7,57.3,71.2,68.1,82.6$ and $90.3 \%$ in the 2 nd experiment (Table 1, Fig. 4). The Condition factors (C) and the Specific Growth Rates (SGR \%) were found to be similar in all groups (Table 1).

This study dealt with different hormone concentrations, application type, application time and survival percentages of larvae that were effective on the sex reversal of the Nile tilapia. The inter-group difference was found significant $(p<0.05)$ in the 1 st experiment in groups that were fed with feed containing different MT in terms of survival rates whereas the inter-group difference among the survival rates was not considered significant ( $>0.05$ ) in the 2nd experiment. According to the histological section samples of the gonads, the rates of male individuals in the population were found to be 57.1 , $69.8,69.4,70.9,86.1$ and $93.7 \%$, respectively in the 1 st experiment while these rates were found to be $49.7,57.3$, $71.2,68.1,82.6$ and $90.3 \%$ in the 2 nd experiment. Accordingly, it was found out that there was a significant difference $(p<0.05)$ among the groups feeding with feeds containing different rates of steroid in terms of sex reversal rates in both experiments. While no differences were observed between the reversal rates obtained with similar doses in both experiments, the highest sex reversal occurred at $50 \mathrm{mgMT} \mathrm{kg}^{-1}$ feed dose and $60 \mathrm{mgMT} \mathrm{kg}^{-1}$ feed dose. The masculinization success was found to be high in comparison to the control groups at doses of $20-40 \mathrm{mgMT} \mathrm{kg}^{-1}$ feed. When the results of different doses were compared with each other, it was found that the results of $50 \mathrm{mgMT} \mathrm{kg}^{-1}$ feed dose and $60 \mathrm{mgMT} \mathrm{kg}^{-1}$ feed dose were not different from each other but were different from the others $\left(0,20,30\right.$ and $40 \mathrm{mgMT} \mathrm{kg}^{-1}$ feed) $(\mathrm{p}<0.05)$. The effect of androgen on sex reversal depends on the type of application such as the method used, dose, fish age and size (Demska-Zakes and Zakes, 1995). In this study as well, it was observed that the dose and type of application directly affected the result although, the actual factor in sex reversal was MT. Therefore, specifying the environmental conditions, hormone type and the method used in such applications is of great importance for performing conscious commercial applications, the results of which can be estimated. Although, MT is used mostly in commercial productions in order to obtain a male population, it is also known that other hormones are also effective (Bart, 2001). In spite of this, the most widely used androgen is MT and this androgen has been tried on $>25$ species of the families Salmonidae, Cichlidae, Cyprinidae, Anabantidae, Poecidae, Cyprinodontidae and Percidae (Malison et al., 1986; Pandian and Sheela, 1995). The most preferred

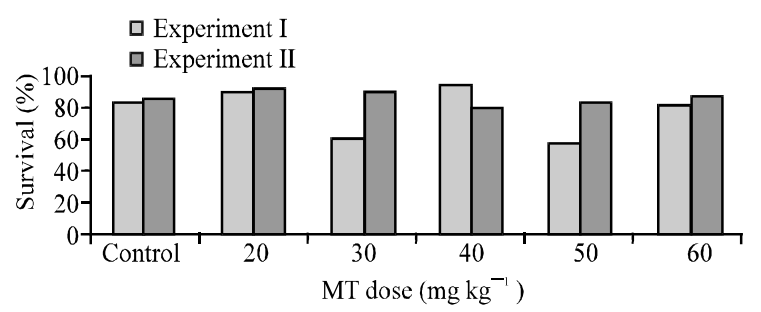

Fig. 3: Survival rates $(\%)$ of the groups to which different doses of MT were applied at the end of the experiment

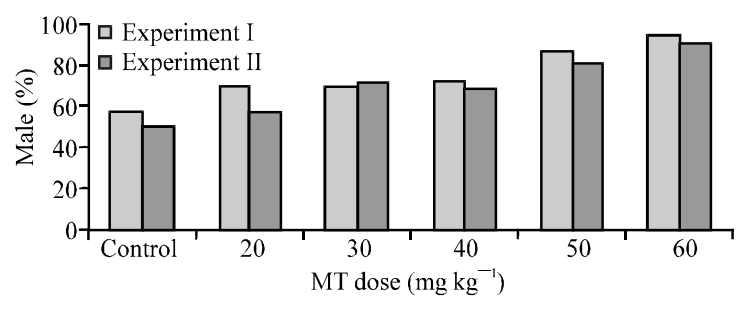

Fig. 4: Percentages of male individuals in groups to which different doses of MT were applied, obtained at the end of the experiment

\begin{tabular}{llllllll}
\multicolumn{2}{l}{ Table 1: The male rate (\%), survival (\%), FCR, SGR (\%), C found in both experiments at the end of the study. E.I; Experiment I, E.II; Experiment II } \\
\hline
\end{tabular}


application is the method of adding steroid to the feed (Hunter and Donaldson, 1983). In this study, the effects of the most preferred method and type of androgen on the Nile tilapia at different doses were found out. Success in sex reversal applications with hormone depends on the gonadal differentiation period.

The gonadal differentiation that determines sex occurs early in tilapia and salmonidae whereas, it occurs on the 40th day after hatching in some species. It was reported that over $95 \%$ of the population was masculinized in 21-28 days when 30-60 $\mathrm{mgMT} \mathrm{kg}^{-1}$ feed with synthetic androgen $17 \alpha$-methyltestosterone was applied orally to the tilapia larvae (7-12 days of age, 9-11 mm TL and 10-15 mg of total weight) (Barry et al., 2007; Green and Teichert-Coddington, 2000) whereas in this study as well, the highest sex reversal occurred at $60 \mathrm{mgMT} \mathrm{kg}{ }^{-1}$ feed dose which was the highest dose in both experiments and a maximum of $93.7 \%$ male population was obtained with orally-administered $60 \mathrm{mgMT} \mathrm{kg}^{-1}$ feed to newly-hatched individuals for 29 days following the consumption of the majority of the yolk sac. Over $82 \%$ male individuals were obtained at $50 \mathrm{mgMT} \mathrm{kg}{ }^{-1}$ feed dose while the rate of males in the population was found to be below $70 \%$ at and below $40 \mathrm{mgMT} \mathrm{kg}^{-1}$ feed. Even if $>95 \%$ of the population can be masculinized with $60 \mathrm{mgMT} \mathrm{kg}^{-1}$ feed dose, the fact that $5 \%$ are females demonstrates that this is not the optimum dose (Phelps et al., 2007). In the studies, where $O$. niloticus eggs were subjected to different doses of $17 \alpha$-Methyltestosterone immersion for $24-96 \mathrm{~h}$, it was reported that besides the fact that about $91 \%$ sex reversals were obtained, the sex reversal rates also increased as the dose amount increased. It is difficult to state that the obtained results upon the increase in hormone dose would be affected positively. In Guppies, in immersion application the survival rate $(51 \%)$ obtained with $25 \mathrm{mg} / 20 \mathrm{~L} 17 \alpha$-MT was reported to be lower than the one obtained with $12.5 \mathrm{mg} / 20 \mathrm{~L}$ dose (Turan et al., 2006). In another sex reversal study on zander (Stizostedion lucioperca), 97\% male population was obtained with $17 \alpha \mathrm{MT}$ administered at $30 \mathrm{mgkg}^{-1}$ dose whereas, $55 \%$ males were obtained at $60 \mathrm{mg} \mathrm{kg}^{-1}$ dose (Demska-Zakes and Zakes, 1995). In this study, no difference was found among the survival rates in groups at different doses ( $p>0.05)$ whereas the sex reversal rate was observed to have increased as the dose increased until the level of $60 \mathrm{mg} \mathrm{kg}^{-1}$.

Even if over $90 \%$ male populations can be obtained by the hormone applications carried out both at egg stage and at larva stage and even if these results which are obtained with oral MT applications are for the time being satisfying the commercial producers, the reasons which will affect consumers negatively such as the fact that $100 \%$ success cannot always be achieved in this method and that the fish are exposed to hormone may indicate that the usability of this application in forming long term production protocols for future may be lost. On the other hand in a study where the effect of MT applications on human health was evaluated, it was found that MT which was suggested to be used for sex reversal at early life stages does not have any negative effects on human food health (Green and Teichert-Coddington, 2000).

\section{CONCLUSION}

There are other studies concerning the absence of any MT remains within the fish until the harvesting size, it is strongly possible that this application be replaced by super male production methods. Even though, such applications are envisaged to become usable on mature candidates only in the protocols of obtaining super males with YY chromosome or super females (XX) for the time being it continues to be one of the most preferred methods in commercial productions due to its advantages such as the fact that the methodology of this application is simple and cheap that no special production stocks are needed and that the hormone administered in small amounts is disposed from the body in a short period of time.

\section{REFERENCES}

Abucay, J.S., 1997. Hormonal sex reversal of tilapias: Ýmplications of hormone treatment application in closed water systems. Aquaculture Res., 28: 841-845.

Barry, T.P., A. Marwah and P. Marwah, 2007. Stability of 17?-methyltesterone in fish feed. Aquaculture, 271: 523-529.

Bart, A., 2001. The application of ultrasound to produce all-male tillapia using immersion protokol. 9th Work Plan, Reproduction Control Research 8 (9RCR8), Final Report. Aquaculture and Aquatic Resources Management Asian Instýtute of Technology Pathumthani, Thailand. http://pdacrsp.oregonstate. edu/pubs/technical/19tch/9RCR8.pdf.

Demska-Zakes, K. and Z. Zakes, 1995. Effect of 17 ?methyltestosterone on gonadal differentiation in pikeperch, Stizostedion lucioperca L. Aquaculture Res., 28: 59-63.

Green, B.W. and D.R. Teichert-Coddington, 2000. Human food safety and environmental assessment of the use of $17 \mathrm{a}$-methyltestosterone to produce male tilapia in the United States. J. World Aquaculture Soc., 31: $337-357$.

Hunter, G.A. and E.M. Donaldson, 1983. Hormonal Sex Control and its Application to Fih Culture. In: Fish Physiology, Hoar, W.S., R.J. Randal and E.M. Donaldson (Eds.). Vol, 9., Academic Press, New York, London, pp: 223-291. 
Macintosh, D.J. and D.C. Little, 1995. Nile Tilapia (Oreochromis niloticus). In: Broodstock Management and Egg and Larval Quality, Bromage, N.R. and R.J. Roberts (Eds.). Chapter 12., Blacwell Scientific Ltd., USA, pp: 277-320.

Mair, G.C. and D.C. Little, 1991. Population control in farmed tilapias. NAGA, ICLARM Q., 14: 8-13.

Malison, J.A., T.B. Kayes, C.D. Best, C.H. Amundson and B.C. Wentworth, 1986. Sexual differantiaton and the use of hormones to control sex in yellow perch (Perca flavences). Can. J. Fish. Aquatic Sci., 43: 25-35.

Pandian, T.J. and S.G. Sheela, 1995. Hormonal induction of sex reversal in fish. Aquaculture, 138: 1-22.

Phelps, R.P., L.L. Lovshin and B.W. Green, 2007. Sex reversal of Tilapia: 17á-metiltestosteron dose rate by environmental and efficacy of bull testes. $\mathrm{PD} / \mathrm{A}$ CRSP Fourteenth Annual Technical Report. http://pdacrsp. oregonstate.edu/pubs/technical/14tch pdf/2.b.4.pdf.
Pompa, T.J. and B.W. Green, 1990. Sex reversal of Tilapia in earthen ponds. Research and Development Series No. 35. International Center for Aquaculture, Alabama Agricultural Experimet Station, Auburn University, USA.,

Rosenstein, S. and G. Hulata, 1994. Sex reversal in the genus Oreochromis: Optimization of feminization protocol. Aquaculture, 89: 329-339.

Turan, F., S. Cek and E. Atik, 2006. Production of monosex male guppy, Poecilia reticulata, by $17 \alpha$-methyltestosterone. Aquacult. Res., 37: 200-203.

Varadaraj, K., S. Sindhu Kumari and T.J. Pandian, 1994. Comparison of conditions for hormonal sex reversal of Mozambique tilapias. Progressive Fish. Culturist., 56: 81-90.

Vera Cruz, E.M. and G.C. Mair, 1994. Conditions for effective androgen sex reversal in Oreochromis niloticus L. Asian. Fish. Sci., 9: 161-167.

Vera Cruz, E.M., G.C. Mair and R.P. Marino, 1996. Feminization of genotypically YY Nile tilapia Oreochromis niloticus L. Asian Fish. Sci., 9: 161-167. 